Motrivivência v. 29, n. 50, p. 90-103, maio/2017

\title{
A AGENDA DO FUTEBOL NO GOVERNO LULA: ações rumo à Copa do Mundo FIFA 2014
}

\author{
Mariângela Ribeiro' \\ Nadson Santana Reis ${ }^{2}$ \\ Wagner Barbosa Matias ${ }^{3}$ \\ Pedro Athaude 4 \\ Edson Marcelo Húngaro 5 \\ Fernando Mascarenhas ${ }^{6}$
}

\section{RESUMO}

O artigo apresenta e discute os temas que permeiam a agenda do futebol no Governo Lula (2003-2010). Para tanto, foi empreendida uma pesquisa documental que implicou em seleção de notícias produzidas e divulgadas pela Assessoria de Comunicação do Ministério do Esporte (ASCON). A organização dos dados - em unidades temáticas redundou na identificação de, pelo menos, quatro eixos temáticos, a saber: gestão dos clubes; financiamento; segurança nos estádios; e Copa do Mundo FIFA 2014. A discussão aponta um processo que supõe adequação da modalidade à lógica de construção dos megaeventos e, pari passu, às diretrizes de privatização/mercantilização.

Palavras-chave: Futebol; Políticas Públicas; Governo Lula

1 Mestra em Educação Física. Professora no Curso de Educação Física da Universidade do Estado da Bahia (UNEB). Guanambi/Bahia, Brasil. E-mail: angelamari.rs@bol.com.br

2 Mestre em Educação Física. Professor de Educação Física do Colégio Pequeno Príncipe e integrante do grupo de pesquisa Avante da Universidade de Brasília (UnB). Guanambi/Bahia, Brasil. E-mail: nadsonsr@hotmail.com

3 Mestre em Educação Física. Servidor do Ministério do Esporte e da Secretaria de Educação do Distrito Federal. Brasília/ Distrito Federal, Brasil. E-mail: wagner.matias@outlook.com

4 Doutor em Política Social. Professor da Faculdade de Educação Física da Universidade de Brasília (UnB). Brasília/ Distrito Federal, Brasil. E-mail: pedroavalone@gmail.com

5 Doutor em Educação Física. Professor da Faculdade de Educação Física da Universidade de Brasília (FEF/UnB). Brasília/Distrito Federal, Brasil. E-mail: marcelohungaro66@gmail.com

6 Doutor em Educação Física. Professor da Faculdade de Educação Física da Universidade de Brasília (FEF/UnB). Brasília/Distrito Federal, Brasil. E-mail: fernando.masca@outlook.com 
V. $29, \mathrm{n}^{\circ}$ 50, maio/2017

\section{INTRODUÇÃO}

O Governo Lula desempenhou papel importante no campo esportivo. E, de maneira especial, no futebol - modalidade esportiva com grande prestígio no país. Para tanto, houve comprometimento político e empenho governamental - inclusive com a participação do próprio presidente Lula - na candidatura do Brasil a sede da Copa do Mundo FIFA 2014.

Como desdobramento disso - mas não somente por isso ${ }^{7}$ - foi flagrante a ampliação e, também, a alteração na agenda esportiva brasileira, com mudanças significativas no padrão de relacionamento entre o Estado e o setor esportivo (MASCARENHAS, 2012).

Nessa direção, o governo de coalizão, liderado pelo Partido dos Trabalhadores (PT), buscou estabelecer novos ordenamentos legais e um conjunto de medidas voltadas à modernização do futebol. São ilustrativas, nesse sentido, as alterações no arranjo institucional, nas formas de financiamento e gestão, bem como no modelo de relacionamento entre Estado e entidades de administração esportiva. Aspectos que, para Mascarenhas et al., (2014), se faziam necessários à adequação do futebol ao mercado esportivo globalizado.

Nessa esteira, a investigação em tela busca analisar a agenda governamental voltada ao futebol no governo Lula, mesmo porque a formação dessa agenda compreende um momento decisivo na formulação de políticas públicas. A qual se caracteriza como um tempo e/ou espaço em que emergem determinados temas, delimitando, assim, um objeto de intervenção governamental (MASCARENHAS et al., 2014).

A questão de partida, portanto, contempla a necessidade de compreensão do princípio organizador e dos temas que implicaram e/ou afetaram a atuação do Governo Federal - no futebol - no período que compreende os anos de 2003 a 2010.

\section{DELINEAMENTO DO ESTUDO}

O estudo - de natureza qualitativa - agrega pesquisa bibliográfica e documental. A primeira responde à necessidade de embasamento teórico a respeito dos principais elementos que permeiam a questão de pesquisa: explicação e discussão dos conceitos de referências e/ou categorias de análise. Já à segunda coube o objetivo de apreender os aspectos que formataram e/ou afetaram a política esportiva, do Governo Lula, voltada ao futebol.

A operacionalização da investigação em questão implicou em levantamento e seleção de notícias produzidas e divulgadas pela Assessoria de Comunicação do Ministério do Esporte (ASCOM) no portal eletrônico do próprio ministério.

O levantamento dos dados - em função do recorte temporal, primeiro e segundo mandatos do Governo Lula - foi realizado a partir do dia 13 de janeiro de 2003 até 31 de dezembro de 2010. Desse modo, a atividade de "pré-análise" (BARDIN, 2010) - realizada a partir da leitura flutuante do material agrupado em torno do descritor 'futebol' - permitiu

7 Há que ressaltar, ainda, a realização dos Jogos Pan-Americanos Rio 2007 e a postulação do Rio de Janeiro a sede dos Jogos Olímpicos/Paralímpicos de 2016 (MASCARENHAS et al., 2014). 
a definição de um 'corpus' de análise constituído por 1.540 notícias. Destas, apenas 256 apontavam o tempo e o lugar do futebol na agenda esportiva brasileira, tomando-o como objeto de ação/intervenção do Governo Federal.

Quanto à base técnica e operacional para o tratamento deste material utilizou-se a análise de conteúdo (BARDIN, 2010; FRANCO, 2005), já que se tinha a pretensão de apanhar o significado presente nas informações, nos enunciados e nos termos expressos nos documentos. Por isso, considerando a frequência dos temas, o conjunto dos dados foi organizado em unidades temáticas ${ }^{8}$, conforme Tabela 01.

Tabela 01: Unidades Temáticas - o futebol no Governo Lula (2003-2010).

\begin{tabular}{lc}
\hline Unidades de contexto & Número de notícias \\
\hline Gestão dos Clubes & 19 \\
Financiamento & 46 \\
Segurança nos Estádios & 76 \\
Copa do Mundo FIFA 2014 & 108 \\
Outros & 07 \\
\hline Total & $\mathbf{2 5 6}$ \\
\hline
\end{tabular}

Fonte: Elaboração dos autores (2015).

A partir disso, passa-se, então, à discussão dos resultados da investigação, cujos recortes de exposição - a serem apresentados a seguir - estão organizados a partir dos temas privilegiados na agenda esportiva relacionada ao futebol no Governo Lula (2003-2010).

\section{GESTÃO DOS CLUBES}

O diagnóstico da situação dos clubes de futebol brasileiros, antes mesmo da chegada de Lula à Presidência da República, apontava - dentre outras coisas - dificuldades e/ou fragilidades na gestão. E, atrelado a isso, persistia problemas financeiros de grandes proporções (MANHÃES, 2002; VERONEZ, 2005).

Nesse contexto, modernizar a gestão dos clubes foi a saída apontada pelo Governo Federal. Para tanto, havia a necessidade de adequação das atividades e/ou práticas de gestão ao ordenamento legal elaborado na sequência de 1988, sobretudo a partir da Lei nº. 9.615/1998 (Lei Pelé) que, não por acaso, preconizava a transformação dos clubes em empresas.

8 Destaca-se, para o conteúdo das unidades temáticas (gestão dos clubes, financiamento, segurança nos estádio e Copa do Mundo FIFA 2014), o importante papel desempenhado pelas Conferências Nacionais de Esporte, as quais tiveram impacto no debate e na reorganização da política esportiva brasileira. Assim, é essencial reconhecê-las como um espaço/tempo privilegiado para a discussão dos temas que marcaram a agenda do futebol no Governo Lula. A despeito das particularidades de cada uma, é emblemático o conteúdo do Plano Decenal de Esporte e Lazer, o qual é resultado da III Conferência e que guarda sintonia - em maior ou menor medida - com os aspectos apresentados nesse texto. 
Nessa perspectiva, surgia, já em 2003, a Lei de Modernização do Futebol (Lei nº. 10.672) que - não obstante - instituía novos princípios para sua gestão, a saber: transparência financeiro-administrativa; moralidade na gestão desportiva; responsabilidade social de seus dirigentes; e tratamento diferenciado em relação ao desporto não profissional (SANTOS, 2011).

Na mesma direção, em 2004, o Ministério do Esporte cria a "Comissão de Futebol e Marketing Esportivo" cujo objetivo englobava: a necessidade de encontrar soluções para a dívida dos clubes; a definição das fontes de financiamento para clubes formadores; os parâmetros para contratos entre jogadores e clubes; bem como a formatação de gestão estratégica na área de marketing; e, além disso, ações voltadas à segurança nos estádios.

Ainda no ano de 2006 era apresentada a "Cartilha para padronização das práticas contábeis dos Clubes de Futebol Profissional". Tal cartilha buscava se afirmar como referência para uniformizar as técnicas de contabilidade utilizadas pelas entidades desportivas e, além disso, orientar sua organização e inserir novos recursos à gestão financeira dos clubes.

O conjunto de tais iniciativas revela, com clareza, a preocupação do Governo Federal com a gestão dos clubes brasileiros, muito embora, a referida preocupação estivesse circunscrita ao reestabelecimento da "saúde" financeira dos clubes - aspecto considerado essencial ao fortalecimento das agremiações esportivas.

Por isso, a modernização da gestão dos clubes, indicada pelo Ministério do Esporte, foi apresentada como elemento basilar à construção de uma imagem positiva em relação ao futebol brasileiro que - não por acaso - se pretendia eficiente, transparente e digno do estigma de "melhor do mundo", alegoria fundamental à disputa do direito de sediar a Copa do Mundo FIFA 2014.

Tal interpretação é incrementada por Proni (2000) que reconhece a influência do modelo europeu de organização esportiva na experiência brasileira, uma vez que identifica: a organização em clubes; a participação do Estado; e a inserção de empresas privadas. Para ele, as mudanças de que tratam esse tópico, causadas pela introjeção e afirmação de uma lógica capitalista de mercado, expõe os clubes e as demais instituições do setor às leis de mercado sem a correspondente preocupação com a ideia de direito público universal.

Desse modo, a propalada modernização da gestão guardou, no governo em questão, sintonia com a tendência do esporte como uma das "atividades econômicas" que mais crescem nos mercados globalizados - aspecto que tem estimulado a entrada de grandes corporações empresariais e tem requerido recursos e/ou métodos modernos de administração/gestão.

\section{FINANCIAMENTO}

A revitalização do futebol brasileiro, sintonizada ao movimento esportivo internacional, supunha reorganização substantiva, sobretudo na questão do seu financiamento que - não por acaso - aparece como temática fundamental na agenda da "grande paixão nacional", mesmo porque a situação financeira dos clubes - classificada como pré-falimentar (SANTOS, 2011) - constituía obstáculo de grande proporção à anunciada modernização. 
Nesse sentido, merece destaque a disposição do Governo Federal em renegociar as dívidas dos clubes, os quais estavam relacionados entre os maiores devedores da Previdência Social (SANTOS, 2011). Resolver tal problema passava, conforme os dirigentes esportivos, pela criação de novas receitas e/ou fontes de financiamento.

É exatamente nessa direção que, em dezembro de 2006, o Governo Federal sanciona a Lei $n^{\circ}$. 11.345, criando - por meio dela - a Timemania, um concurso prognóstico destinado ao desenvolvimento das entidades esportivas que cuidavam do futebol no país. Para tanto, a nova loteria respondia à necessidade de novas receitas, uma vez que - dos recursos arrecadados - $22 \%$ iriam para os clubes. O repasse dessa porcentagem, no entanto, estava condicionado à quitação das dívidas dos clubes com a União.

Para Agnelo Queiroz [então Ministro do Esporte] a resolução definitiva das dívidas dos clubes era, pelo exposto, 'favas contadas', mesmo porque, pra ele, a nova loteria seria uma garantia de que os clubes iriam sanear as dívidas e - por isso - não voltaria à situação de falência em que se encontravam. Para o presidente Lula, por outro lado, tal intervenção se fazia necessária não só por se tratar de uma modalidade esportiva que embala a paixão do brasileiro, mas, também, por ser um setor com grande potencial para a geração de emprego e renda (BOUDENS, 2007).

Para Castellan (2011, p.52, grifo nosso):

Com a Timemania o poder público buscou regularizar a situação dos clubes de futebol, [...] e desta forma estavam impossibilitados de receber dinheiro público. O Governo então cria uma loteria cuja principal motivação é fazer com que os clubes inadimplentes possam voltar a receber recursos federais.

O argumento em destaque confere importância à loteria, mesmo porque, por meio dela, os clubes puderam acessar, enfim, a Certidão Negativa de Débito e Tributos e Contribuições Federais (CND), qualificando-os para a obtenção de incentivos fiscais e patrocínios públicos.

Apesar disso, conforme estudo realizado pela Pluri Consultoria (2013), apenas Vasco, Coritiba, Goiás e Atlético Paranaense diminuíram suas dívidas com a União. Fato que apontou descompassos entre os objetivos anunciados e os resultados apresentados. Fragilidade que levou, mais uma vez, o Governo Federal a estudar novos mecanismos para refinanciar as dívidas dos clubes.

Já em 2007 era implantada a Lei de Incentivo ao Esporte (Lei $n^{\circ}$. 11.438) que também auxiliava os clubes de futebol profissional. Seu texto previa renúncia fiscal de parte do Imposto de Renda (IR) para ser investido em projetos esportivos. Desse modo, pessoas físicas poderiam doar ou usar - como patrocínio - até $6 \%$ do imposto devido e pessoas jurídicas - empresas, clubes sociais, entidades de classe, entre outros -, até $4 \%$.

Por isso, a referida lei pode ser considerada como uma forma simplificada de uso dos recursos do fundo público ${ }^{9}$, uma vez que os dividendos dela decorrentes poderiam ser

9 Conforme Salvador (2010) o fundo público envolve toda a capacidade de mobilização de recursos que o Estado tem para intervir na economia, além do próprio orçamento, as empresas estatais, a política monetária comandada pelo Banco Central para socorrer as instituições financeiras etc. A expressão mais visível do fundo público é o orçamento estatal. 
"[...] executados diretamente por organizações não governamentais ou entes governamentais fora da esfera federal" (TRIBUNAL DE CONTAS DA UNIÃO, 2013, p. 02).

Para Matias et al. (2015), o futebol foi a modalidade esportiva que mais se beneficiou da Lei de Incentivo, seguido de judô e atividades aquáticas. Dados divulgados pelo próprio Ministério do Esporte, apresentados no Gráfico 02 - a seguir, dão conta da dimensão dessa medida no financiamento do futebol brasileiro:

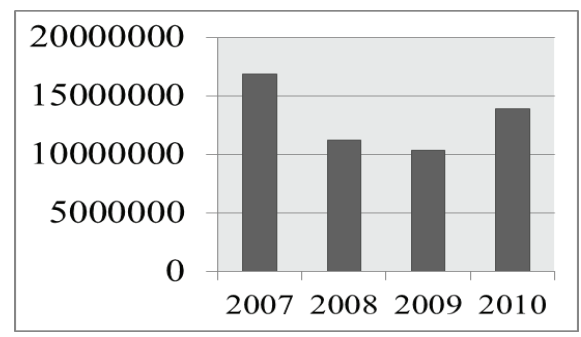

Gráfico 02: Arrecadação dos clubes de futebol pela Lei de Incentivo.

Fonte: Elaboração dos autores (2015).

Conforme o gráfico, entre 2007 e 2010, dos projetos aprovados na categoria "Alto Rendimento", mais de R\$52 milhões foram destinados às agremiações esportivas de futebol - clubes. Aspecto que qualifica a Lei de Incentivo como uma fonte de recursos importante ao futebol nacional. O Gráfico 03, na sequência, complementa a informação em destaque, uma vez que aponta os cinco clubes que mais captaram recursos:

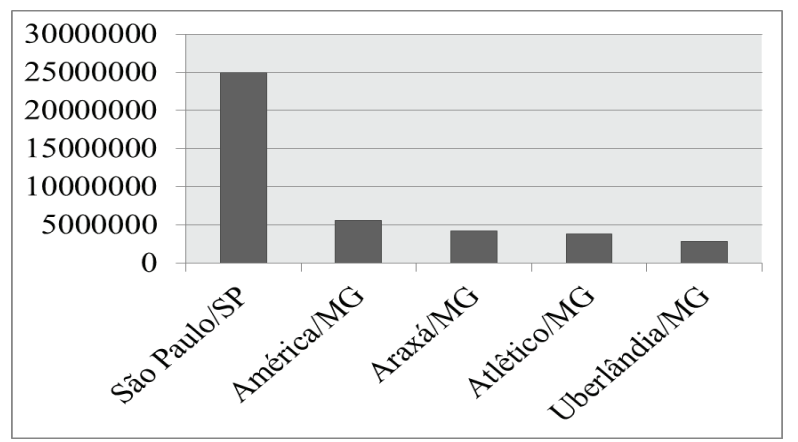

Gráfico 03: Principais clubes a captarem recursos a partir da Lei de Incentivo entre 2007/2010. Fonte: Elaboração dos autores (2015).

São Paulo (SP), América, Araxá, Atlético e Uberlândia (MG) figuram como os cinco maiores beneficiários. Um dado importante nessa representação gráfica é a disparidade/ concentração de recursos - em relação ao segundo, o primeiro clube ganha quase quatro vezes mais e, além disso, nessa representação, só aparecem clubes da região sudeste. 
Desse modo, o formato de financiamento, privilegiado na Lei de Incentivo, não parece guardar qualquer relação com os princípios de equidade, desconcentração e justiça social que supõe a operacionalização do direito social ao esporte.

Assim, o dispositivo legal em questão implica em perda do poder discricionário do Estado, uma vez que o isenta da formulação, execução e/ou desenvolvimento de políticas públicas para o setor. Fatos que levaram Matias et al. (2015) a caracterizá-la como uma "contrarrevolução" à premissa do esporte como direito social universal.

\section{SEGURANÇA NOS ESTÁDIOS}

O combate à violência nos estádios brasileiros aparece como um tema em destaque no conjunto das notícias produzidas e divulgadas pela ASCON. Aspecto que demonstra a preocupação do Governo Federal em sanear os índices de violência que maculavam o espetáculo esportivo no país.

No entanto, mais do que uma questão de segurança pública, o tema adquire envergadura política em função do desejo do Governo brasileiro em sediar a Copa do Mundo FIFA 2014. O discurso do Ministro Agnelo, nesse sentido, é ilustrativo: "A ideia é deixar o Brasil pronto até 2007, com um bom futebol e uma boa estrutura".

Cabe ressaltar, nessa direção, que a questão da segurança nos estádios constitui elemento fundamental no conjunto das exigências da Federação Internacional de Futebol (FIFA) aos países que pleiteiam a realização de um mundial.

Assim, de um seminário realizado pelo ME, em Brasília, em março de 2003, com objetivo de construir o "bom futebol" - como anunciava Agnelo Queiroz - saiu a "Carta de Brasília sobre Segurança nos Estádios". Sintonizada ao desejo de sediar o mundial de futebol, seu texto apresentava uma série e medidas preventivas para a garantia da paz nas arenas esportivas.

No mesmo ano, não por acaso, deu-se a criação do "Estatuto de Defesa do Torcedor" (EDT) - considerado um marco na história esportiva do país (SANTOS, 2011). O principal argumento para a sua criação orbitava em torno da necessidade de aperfeiçoar as normas de sociabilidade nos espaços públicos e privados destinados às diferentes práticas esportivas.

Para Reis (2010) o EDT representou um grande avanço na elaboração de normas específicas e atribuição de responsabilidades na organização de eventos esportivos. Todavia, em sua avaliação, há entraves que envolvem desde a limitação da capacidade de público; a não qualificação das punições; as imprecisões das responsabilidades; a ausência quanto à numeração e ao tipo de assento; assim como a divisão de setores nas arenas esportivas; e a falta de acompanhamento das ações legais necessárias para a entrada em vigor de todos os artigos da lei.

Mezzadri et al. (2011) reconhecem que a implementação do EDT poderia representar uma contribuição na reorganização do "habitus" social, desdobrando na inauguração e na efetivação de novas formas de se gerir, organizar e consumir o futebol. 
Ainda sobre a temática em questão, já em janeiro de 2004, por meio de um Ato do Presidente da República, foi criada a Comissão Nacional de Prevenção da Violência e Segurança nos Espetáculos Esportivos (CONSEGUE) - a qual era resultado de uma série de debates sobre segurança nos estádios promovida pelo Ministério do Esporte.

É, também, emblemático - nesse sentido - o lançamento, pela Federação Paulista de Futebol (FPF), de um programa piloto, com medidas baseadas em propostas da Comissão Paz no Esporte, criada pelo ME junto ao Ministério da Justiça (MJ).

Em 2009, o próprio presidente Lula anunciou o 'Projeto Torcida Legal' que previa medidas para segurança e conforto dos torcedores. Assim, a assinatura do Projeto de Lei $n^{\circ} .4 .869 / 09$, que alterava o EDT, tipificava como crimes esportivos ações como tumultos, manipulação de resultados e venda irregular de ingressos.

Orlando Silva, novo Ministro do Esporte, avaliou, de forma conclusiva, que tais medidas tinham peso histórico para o futebol brasileiro: "Estamos no caminho certo de um ciclo virtuoso nos estádios. Essas medidas têm todo nosso entusiasmo e esperamos que esse processo seja coroado com o Brasil sediando a Copa de 2014". Por isso, para ele, "[...] o Brasil tem dado passos positivos no que diz respeito à segurança e comodidade nos estádios. O torcedor passa a ser mais respeitado, considerado como cliente".

Aqui cabe a observação de Santos e Mascarenhas (2011), com a qual se alinha a fala do ministro: o conjunto das medidas voltadas à segurança e comodidade nos estádios, em contradição com a noção de direito previsto pela Constituição Federal, transforma o espetáculo esportivo em mercadoria e o cidadão em consumidor. "O torcedor, outrora percebido como devedor eterno de sua devoção ao clube por seu amor à camisa, é encarado como um "mercado consumidor", que tem potencial de compra e necessidades a serem atendidas" (CARVALHO; GONÇALVES E ALCÂNTARA, 2005, p.14).

\section{COPA DO MUNDO FIFA 2014}

A Copa do Mundo FIFA 2014 aparece como tema de maior destaque na agenda esportiva brasileira, mesmo porque, no Governo Lula, o fortalecimento e a reestruturação do futebol nacional supunha a conquista do direito de sediar seu mundial.

O presidente Lula, em reiteradas oportunidades, manifestou preocupação em reafirmar a disposição do Brasil para sediar a Copa. A título de exemplo, em encontro com o então presidente da FIFA, Joseph Blatter, Lula ratificou o compromisso do governo brasileiro em garantir a infraestrutura necessária.

Para Agnelo Queiroz, então Ministro do Esporte, o rodízio de continentes-sede, a força brasileira no futebol e o comprometimento do Governo Federal viabilizariam o sucesso da candidatura brasileira. O que, para ele, se desdobraria em "[...] melhoria técnica das estruturas ligadas ao futebol e no desenvolvimento socioeconômico do país, gerando milhares de empregos diretos e indiretos".

A despeito da candidatura única, ações foram empreendidas no sentido de fortalecer as pretensões do país em sediar o evento. Por meio de Decreto Presidencial, de $1^{\circ}$ 
de novembro de 2006, criou-se um Grupo de Trabalho Interministerial ${ }^{10}$ para definir a estruturação do país para abrigar o maior evento de futebol do planeta.

Além da estrutura institucional, o Brasil se comprometeu a respeitar aquilo que ficou popularmente conhecido como "padrão FIFA de realização de eventos". O dossiê de candidatura brasileiro previa o atendimento às onze exigências presentes no "Caderno de Encargos da FIFA ${ }^{11 " \text {. }}$

Preenchidas todas as exigências, o Brasil foi confirmado país sede da Copa do Mundo FIFA 2014. Logo após o anúncio, o Presidente Lula fez um pronunciamento emocionado:

[...] o país tem uma tarefa incomensurável pela frente, mas que será abraçada por toda a nação. Vocês verão no Brasil grandes jogadores, a natureza exuberante e grandes estádios, mas o que vai emocionar vocês mesmo, tenho certeza, será o comportamento extraordinário do nosso povo ${ }^{12}$.

Assim, considerando que coube ao Governo Federal e às entidades de administração esportiva internacional e nacional centralizar a decisão sobre a vinda da Copa do Mundo FIFA 2014 para o país, observa-se, novamente, o fenômeno - identificado por Coutinho (2006) - de conciliação de interesses "pelo alto", obstaculizando a construção de decisões democráticas.

De acordo com Coutinho (2006), nesse tipo de "acordo despótico" existe uma manifestação das camadas subalternas por meio de "um subversivismo esporádico e elementar" (expressão retirada de Gramsci), ao passo que as classes dominantes reagem a esse movimento embrionário com manobras pelo alto, que implicam acordo e conciliação entre segmentos "modernos" e os segmentos "arcaicos" desses grupos.

As ações do Governo Federal seguiram no sentido de preparar o país para o mundial. A etapa seguinte era a escolha das cidades-sede dos jogos, a qual ocorreu em duas fases: a apresentação dos temas gerais da Copa e os encontros individuais da Confederação Brasileira de Futebol (CBF) com os representantes das cidades candidatas.

Depois da escolha, na $1^{\text {a }}$ Reunião com os prefeitos das cidades-sede, o Ministro do Esporte declarou que o Governo Federal definiria conjuntamente uma Matriz de Responsabilidades. Grosso modo, o referido documento buscava firmar um regime de mútua-cooperação entre os governos federal, estadual e municipal estabelecendo, para isso, as atribuições, responsabilidades e contribuições, além do sistema de monitoramento,

10 O Grupo foi formado pelo ME, que coordenaria outros ministérios: Ministério da Justiça, das Cidades, do Turismo, dos Transportes, da Fazenda, do Planejamento, Orçamento e Gestão (MPOG), das Relações Exteriores, Casa Civil e Presidência da República. A CBF, que representa o Brasil perante a FIFA, participou como convidado permanente. Cabia a esse Grupo de Trabalho a tarefa de discutir as garantias governamentais para a realização da Copa do Mundo FIFA 2014.

11 Ratificando o conteúdo do dossiê, o Governo brasileiro comprometeu-se em cumprir os onze aspectos exigidos pela FIFA, a saber: decisões de pré-construção, orientação do campo, segurança, estacionamentos, área de jogo, vestiários e acessos, conforto do público, hospitalidade, mídia, energia e iluminação, sustentabilidade.

12 "Faremos a melhor Copa da história da FIFA, garante Ministro Orlando Silva". Disponível em: < http://www. esporte.gov.br/ascom/pesquisanoticia >. Acesso em: 18 mai. 2010. 
dos recursos financeiros e do comitê para coordenação, acompanhamento e avaliação.

Sobre o financiamento para adequação dos estádios às exigências da FIFA, os discursos apontavam que, a sua maior parte, viria da iniciativa privada. O conteúdo dessas afirmações foi modificado sob a alegação da falta de liquidez dos clubes de futebol e do endividamento dos estados e municípios (CÂMARA DOS DEPUTADOS, 2010).

Confirmando os prognósticos, o documento "Copa 2014: desafios e responsabilidades" apontou que os recursos para os preparativos da Copa seriam majoritariamente realizados pelo poder público, destinando substanciais parcelas da arrecadação dos impostos para a realização de obras de infraestrutura, bem como para a construção e revitalização de estádios.

O presidente Lula era avesso à ideia de utilizar recursos do orçamento para ações vinculadas à Copa e, portanto, emitiu orientações no sentido de que fossem ofertadas linhas de financiamento para investimentos em estádios e saneamento, por intermédio do Banco Nacional de Desenvolvimento Econômico e Social (BNDES) e do Ministério das Cidades. Em outubro de 2009, o presidente validava as condições do financiamento para reforma ou construção dos estádios.

Para que a sociedade pudesse acompanhar os gastos com a realização do mundial, o ME lançou um portal na internet denominado "Rede de Fiscalização e Controle da Copa de 2014". O Tribunal de Contas da União (TCU) lançou, também, um modelo de fiscalização de ações relacionadas ao referido evento. De acordo com o Ministro do Esporte, a iniciativa

[...] é mais um sinal de que o Brasil está unido, mobilizado e ativo em torno da preparação Mundial de Futebol. A iniciativa do TCU, junto aos Tribunais de Contas dos Estados e dos Municípios, soma-se a outras igualmente importantes, que visam ampliar a transparência e garantir a fiscalização de cada centavo do dinheiro público que será investido na preparação do país para a Copa de 2014.

Em janeiro de 2010, o Governo Federal apresentou à FIFA o PL n ${ }^{\circ}$ 716/2010, que tratava de isenções tributárias às empresas que fornecem produtos e serviços na organização e realização da Copa das Confederações FIFA 2013 e da Copa do Mundo FIFA 2014. O presidente Lula também assinou um Projeto de Lei Complementar (PLC) $\mathrm{n}^{\circ}$. 579/2010, tratando da isenção do Imposto Sobre Serviço (ISS), que é de competência dos municípios e do DF, e o Decreto que instituiu o Comitê Nacional de Proteção de Direitos da Copa do Mundo 2014, para proteção da propriedade intelectual e dos direitos comerciais da FIFA no país.

Cabe destacar que esses compromissos, posteriormente, foram ratificados e oficializados por um conjunto de leis: Lei n⿳ 12.350, de 20 de dezembro de 2010, Lei Geral da Copa (Lei ${ }^{\circ} 12.663$, de 5 de junho de 2012) e pela Lei no 12.780, de 9 de janeiro de 2013.

No dia 14 de janeiro de 2010, foi publicado Decreto no qual o presidente Lula criou o Comitê Gestor da Copa do Mundo FIFA 2014 - CGCOPA 2014 - que tinha como objetivo definir, aprovar e supervisionar as ações previstas no "Plano Estratégico das Ações do Governo Brasileiro para a realização da Copa". 
A criação de organizações temporárias e de medidas extraordinárias pelo Governo Federal teve o intuito de cumprir os compromissos assumidos junto à FIFA quando da escolha do Brasil como sede da competição. Ao fim e ao cabo, tais medidas tiveram a finalidade de fornecer garantias de lucratividade aos parceiros comerciais da FIFA, mantendo diretrizes de reserva de mercado a essas empresas, mesmo por que:

[...] os Estados nacionais restringem-se a: cobrir custo de algumas infraestruturas (sobre as quais não há interesse de investimento privado), aplicar incentivos fiscais, garantir escoamentos suficientes e institucionalizar processo de liberalização e desregulamentação, em nome da competitividade (BEHRING, 2008, p. 59, grifo da autora).

Assim, segundo Husson (1999, apud BEHRING, 2008), as funções econômicas do Estado se restringem ao intento de tornar os territórios nacionais mais atrativos às inversões estrangeiras, concedendo aos Estados nacionais um papel subordinado aos interesses financeiros internacionais.

\section{CONSIDERAÇÕES FINAIS}

O estudo da formatação/configuração da agenda do futebol, no Governo Lula, sugere, pelo menos, quatro temas de grande relevância: gestão dos clubes; financiamento; segurança nos estádios; e Copa do Mundo FIFA 2014. Por isso, o exercício aqui desenvolvido busca estabelecer uma problematização inicial acerca do comportamento dessa agenda.

Nesse sentido, a despeito dos limites que toma o debate aqui apresentado, é imprescindível ressaltar sua importância para a compreensão do conjunto das políticas voltadas ao futebol nacional. Assim, cabe destacar o surgimento - nesse período - de um novo padrão de organização das políticas esportivas, capitaneado pela realização dos megaeventos esportivos. O atendimento a esse novo padrão se desdobrou na implementação de ações no campo do financiamento, da estrutura, da legislação e da gestão, recrudescendo o projeto de construção do futebol brasileiro sintonizado com os grandes eventos esportivos. Os argumentos que sustentam/atestam tal constatação orbitam em torno da:

1. Introjeção e afirmação definitiva de uma lógica capitalista de mercado nas atividades e/ou práticas de gestão dos clubes de futebol, sob a orientação do próprio Estado brasileiro que - não obstante - já experimentou fortes influências neoliberais, com sérios prejuízos à noção pública de direito social ao esporte;

2. Aceleração dos processos de transformação dos clubes em empresas, do espetáculo esportivo em mercadoria e, consequentemente, do torcedor em consumidor;

3. Adoção de padrões de financiamento que viabilizam e intensificam o abandono dos princípios de equidade e justiça social;

4. Perda do poder discricionário do Estado ante as políticas de futebol e, concomitantemente, a ingerência de novos agentes não governamentais; 
V. $29, \mathrm{n}^{\circ} 50$, maio/2017

5. Conciliação de interesses "pelo alto", obstaculizando a construção de decisões coletivas, como foi o caso da candidatura brasileira à realização da Copa FIFA 2014;

6. Perspectiva de uso da referida modalidade no projeto de tornar o território brasileiro atrativo às inversões estrangeiras, implicando em papel subordinado aos interesses financeiros internacionais;

Desse modo, a propalada modernização do futebol brasileiro pode ser entendida como um processo de transformação da modalidade em produto da indústria global de entretenimento, pautada na gestão do espetáculo, para a qual a administração empresarial passa a ser considerada a solução dos problemas da modalidade, mesmo porque amparada na lógica da mercantilização e privatização do esporte.

Por conseguinte, o ímpeto de modernizar o futebol, trata-se de mais um episódio em que a tentativa de "inovar" acaba reforçando os atrasos atávicos, preservando elementos do passado e se desenvolvendo de forma antidemocrática.

\section{REFERÊNCIAS}

BARDIN, L. Análise de conteúdo. 4. ed. Lisboa: Edições 70, 2010.

BEHRING, E. R. Brasil em contrarreforma: desestruturação do Estado e perda de direitos. 2. ed. São Paulo: Cortez, 2008.

BOUDENS, E. P. J. O financiamento do esporte no primeiro mandato de Lula (2003-2006). São Paulo: T + 8; Usinas de Letras, 2007.

BRASIL. Lei 9.615 de 24 de março de 1998 (Lei Pelé). Disponível em: < http://www. planalto.gov.br/ccivil_03/leis/l9615consol.htm >. Acesso em: 12 set. 2014.

. Lei $\mathbf{n}^{\circ} \mathbf{1 0 . 6 7 1}$, de 15 de maio de 2003. Disponível em: < http://www.planalto. gov.br/ccivil_03/leis/2003/L10.671.htm >. Acesso em 15 set. 2014.

. Lei $\mathbf{n}^{\circ}$ 10.672, de 15 de maio de 2003. Disponível em: < http://www.trtsp.jus.br/ geral/tribunal2/LEGIS/Leis/10672_03.html >. Acesso em 15 set. 2014.

. Lei $\mathbf{n}^{\circ} \mathbf{1 1 . 3 4 5}$, de 14 de setembro de 2006. Disponível em: < http://www2.camara. leg.br/legin/fed/lei/2006/lei-11345-14-setembro-2006-545515-normaatualizada-pl. html >. Acesso em 15 set. 2014.

. Lei $\mathbf{n}^{\circ}$ 11.438, de 29 de dezembro de 2006. Disponível em: < http://www.planalto. gov.br/ccivil_03/_ato2004-2006/2006/lei//11438.htm >. Acesso em 15 set. 2014.

. Lei $\mathbf{n}^{\circ} \mathbf{1 2 . 3 5 0}$, de 20 de dezembro de 2010. Disponível em: < http://www. planalto. gov.br/ccivil_03/_ato2007-2010/2010/Lei/L12350.htm >. Acesso em: 15 ago. 2015.

. Lei no 12.663, de 05 de junho de 2012. Disponível em: < http://www.planalto. gov.br/ccivil_03/_ato2011-2014/2012/Lei/L12663.htm >. Acesso em: 15 ago. 2015.

. Lei $\mathbf{n}^{\circ}$ 12.780, de 09 de janeiro de 2013. Disponível em: < http://www2.camara. leg.br/legin/fed/lei/2013/lei-12780-9-janeiro-2013-775048-normaatualizada-pl.html > . Acesso em: 15 ago. 2015. 
. MINISTÉRIO DO ESPORTE. Carta de Brasília sobre segurança nos estádios. Disponível em: <http://www.planalto.gov.br/ccivil_03/leis/2003/L10.671.htm > . Acesso em 14 de set. 2015.

CÂMARA DOS DEPUTADOS. Comissão de Fiscalização Financeira e Controle. Subcomissão Permanente para Acompanhamento, Fiscalização e Controle de Recursos Públicos destinados à Copa de 2014 e às Olimpíadas de 2016. Copa 2014: desafios e responsabilidades. Brasília: Câmara dos Deputados, Edições Câmara, 2010.

CARVALHO, C. A; GONÇALVES, J. C. S.; ALCÂNTARA, B. C. S. Transformações no contexto do futebol brasileiro: o Estado como agente de mudança. Revista Eletrônica de Gestão Organizacional. v. 3, n. 1. p. 5-18, jan./abr. 2005.

CASTELAN, L. P. As conferências Nacionais de Esporte na configuração da política esportiva e de lazer no Governo Lula (2003-2010). (Dissertação de Mestrado - Programa de Pós-graduação em Educação Física). Faculdade de Educação Física - Universidade Estadual de Campinas. Campinas, 2011.

COUTINHO, C. N. Intervenções: o marxismo na batalha das ideias. São Paulo: Cortez, 2006. FRANCO, M. L. P. B. Análise do conteúdo. 2. ed. Brasília: Líber Livro, 2007.

MANHÃES, E. D. Políticas de Esportes no Brasil. Rio de Janeiro: Paz e Terra, 2002.

MASCARENHAS, F. Megaeventos esportivos e Educação Física: alerta de tsunami. Revista Movimento, Porto Alegre, v. 18, n. 01, p. 39-67, jan./mar. de 2012.

MASCARENHAS, F. et. al. O bloco olímpico: Estado, organização esportiva e mercado na configuração da agenda Rio 2016. Revista da ALESDE, Curitiba, v. 2. n. 2. p. 15-32, out. 2012.

MATIAS, W. B. et al. A Lei de Incentivo Fiscal e o (não) direito ao esporte no Brasil. Revista Movimento, Porto Alegre, v. 21, n. 1, p. 95-110, jan./mar. de 2015.

MAZZADRI, F. M. et al. As interferências do Estado brasileiro no futebol e o estatuto de defesa do torcedor. Revista Brasileira Educação Física e Esportes. São Paulo, v. 25, n. 3, p. 407-416, jul./set. 2011.

PRONI, M. W. A metamorfose do futebol. Campinas: UNICAMP/IE, 2000.

REIS, H. H. B. O espetáculo futebolístico e o Estatuto de Defesa do Torcedor. Revista

Brasileira de Ciências do Esporte, Campinas, v. 31, n. 3, p. 111-130, maio 2010.

SALVADOR, E. Fundo público e seguridade social no Brasil. São Paulo: Cortez, 2010.

SANTOS, M. R. O futebol na agenda do Governo Lula: um salto de modernização (conservadora) rumo a Copa do Mundo FIFA 2014. (Dissertação de Mestrado em Educação Física - UnB) Brasília, 2011.

SANTOS, M. R.; MASCARENHAS, F. Estatuto de Defesa do Torcedor (consumidor) um novo dispositivo político e legal na era do esporte espetáculo. Anais do XVII Congresso Brasileiro de Ciências do Esporte e IV Congresso Internacional de Ciências do Esporte. Disponível em: < http://cbce.tempsite.ws/congressos/index.php/ XVII_CONBRACE/2011/paper/view/3696/1549> Acesso em: 25 mar. 2014.

VERONEZ, L. F. C. Quando o Estado joga a favor do privado: as políticas de esporte após a Constituição Federal de 1988. (Tese Doutorado em Educação Física - Unicamp) Campinas, 2005. 


\title{
SOCCER IN LULA'S GOVERNMENT'S AGENDA: a shift of modernization (conservative) toward the 2014 FIFA World Cup
}

\begin{abstract}
The paper presents and discusses the themes that permeate the soccer agenda in Lula's government (2003-2010). Therefore, a documentary research that implied in selection of news produced and published by the Ministry of Sport Press Office (ASCON) was undertaken. The organization of data - in thematic units - resulted in the identification of, at least, four themes, namely: management of clubs; financing; security in stadiums; and FIFA World Cup 2014. The discussion suggests a process that assumes adequacy of the genre to the construction logic of mega events and, pari passu, the guidelines of privatization/commercialization.
\end{abstract}

Keywords: Soccer; Public Policy; Lula's Government

\section{EL FÚTBOL EN LA AGENDA DEL GOBIERNO LULA: un salto de modernización (conservadora) hacia el mundial de la FIFA 2014}

\section{RESUMEN}

El artículo presenta y discute los temas que impregnan el programa de fútbol en el gobierno de Lula (2003-2010). Por ello se realizó una investigación documental que resultó en la selección de las noticias producido y publicado por la Oficina de Prensa del Ministerio de Deporte de Brasil. La organización de los datos - en unidades temáticas - dio como resultado la identificación de, al menos, cuatro temas, a saber: la gestión de los clubes; financiación; la seguridad en los estadios; y el Mundial de la FIFA 2014. La discusión sugiere un proceso que asume la adecuación del deporte según la lógica de construcción de los mega-eventos y, al mismo ritmo, las directrices de la privatización/ comercialización.

Palabras clave: Fútbol; Políticas Públicas; Gobierno de Lula

Recebido em: março/2016 Aprovado em: agosto/2016 